\title{
Microplastics as Vectors of Chromium and Lead during Dynamic Simulation of the Human Gastrointestinal Tract
}

\author{
Verónica Godoy *, Antonio Martínez-Férez, María Ángeles Martín-Lara *ⓘ,

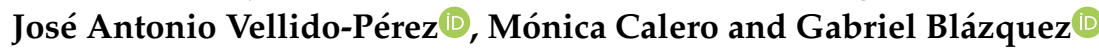

Department of Chemical Engineering, Faculty of Sciences, University of Granada, Avda. Fuentenueva s/n, 18071 Granada, Spain; amferez@ugr.es (A.M.-F.); javellido@ugr.es (J.A.V.-P.); mcaleroh@ugr.es (M.C.); gblazque@ugr.es (G.B.)

* Correspondence: vgcalero@ugr.es (V.G.); marianml@ugr.es (M.Á.M.-L.)

Received: 16 May 2020; Accepted: 9 June 2020; Published: 11 June 2020

\begin{abstract}
The human body is exposed to the ingestion of microplastics that are often contaminated with other substances, which can be released into our body. In this work, a dynamic in-vitro simulator of the gastrointestinal tract based on a membrane reactor has been used for the first time to study the release, bioaccessibility, and bioavailability of chromium $(\mathrm{Cr})$ and lead $(\mathrm{Pb})$ from polyethylene and polypropylene microplastics previously contaminated in the laboratory. The results showed that $23.11 \%$ of the initial $\mathrm{Cr}$ and $23.17 \%$ of the initial $\mathrm{Pb}$ present in microplastics were able to cross the tubular membrane, simulating the intestinal absorption phase. The $\mathrm{pH}$ evolution during the gastric phase and the duodenal phase, the interaction mechanisms with physiological fluids, and the properties of the polymers, such as specific surface, porosity, and/or surface degradation, affected the kinetics of release from the microplastics and the behavior of both heavy metals. Cr was released very early in the gastric phase, but also began simultaneously to precipitate quite fast, while $\mathrm{Pb}$ was released slower and in less quantity than $\mathrm{Cr}$, and did not precipitate until the beginning of the duodenal phase. This study shows, for the first time, how useful the dynamic gastrointestinal simulator is to study the behavior of microplastics and some problematic heavy metals along the human gastrointestinal tract, and can serve as a reference for future studies focused on the effects of these substances in the human body.
\end{abstract}

Keywords: gastrointestinal dynamic simulator; microplastic pollution; human health; intestinal absorption; heavy metals

\section{Introduction}

Concern for microplastics and their environmental impact has been growing in recent years. These particles can be manufactured with a purpose (i.e., exfoliating particles in cosmetics) or can result from the breakdown of larger plastics [1]. There are numerous sources of microplastic emissions into aquatic environments and the atmosphere-most notably, tire wear and washing of synthetic textile garments [2,3]. Currently, microplastics are present in all aquatic environments, including oceans, seas, rivers, and lakes of the entire planet, in addition to being deposited and accumulated in the sand of beaches, estuaries, river basins, and all kinds of landfills [4,5]. These particles also pollute the atmosphere and the air people breathe, and their presence has even been detected in the ice and snow of several highland environments, indicating the great geographical dispersion of microplastics [6-8].

One of the main problems related to microplastics is their capacity to carry chemical pollutants and additives [9]. Furthermore, these substances can be released into the gastrointestinal tracts of 
organisms when microplastics are ingested [10]. Some of the most common pollutants in microplastics are metals and heavy metals, such as chromium, iron, lead, or titanium [11-13]. These metals can be indirectly adsorbed onto the microplastics in aquatic environments or directly added to plastics as metal additives to enhance their properties during the manufacturing process. For example, Godoy et al. [14] examined the adsorption behavior of five types of microplastics on cadmium, cobaltum, chromium, copper, nickel, lead, and zinc in different aquatic systems. The results revealed that $\mathrm{Cr}$ and $\mathrm{Pb}$ were the most adsorbed metals by microplastics in a relatively short period of time. Holmes [13] also found that polyethylene (PE) pellets could adsorb considerable amounts of $\mathrm{Cr}$ and $\mathrm{Pb}$. This author demonstrated, through the simulation of an avian gizzard, that some metals, such as $\mathrm{Mn}, \mathrm{Zn}, \mathrm{Fe}$, or $\mathrm{Pb}$, adhered to the surfaces of the pellets, could be released, and could become bioaccessible to the birds' gastrointestinal tracts as well.

In addition, evidence of microplastics has also been found in various foods and beverages that people ingest, such as mollusks, bivalves and fish, salt, beer, honey, and bottled water [15-18]. Schwabl et al. [19] demonstrated the presence of microplastics in human stool, at least 20 particles per 10 grams of sample in adults, indicating a significant intake of these microparticles. Other authors have estimated the annual human intake of microplastics to be more than 40,000 particles [17]. When metal-contaminated microplastics enter the human body through food or drink, the release of these metals into the digestive tract may occur. Liao and Yang [20] found that $\mathrm{Cr}$ (III) and Cr (VI) present in microplastics were released into the simulated human gastrointestinal tract, mainly in the gastric phase, influenced by the action of gastric juices. However, the effects of microplastics on the human body are not yet very clear. There is a great lack of knowledge about the role played by the contaminants they carry and the additives added to the human body. With regard to metals, some of them, such as $\mathrm{Zn}, \mathrm{Pb}, \mathrm{Cr}, \mathrm{Co}$, or $\mathrm{Ti}$, are added to plastics as pigments, stabilizers, or for resistance to degradation [21]. Their toxicity in humans depends on many factors, including dose and level of exposure, age, sex, or genetics. However, it has been demonstrated that high concentrations of metals can cause cell and tissue damage as well as estrogenic reactions [22,23].

Gastrointestinal simulators are relatively recent, but can accurately predict the pharmacokinetics of drugs, and could thus serve as a research and development (R\&D) tool to study the in-vitro transit of these metal-contaminated microplastics through the digestive tube. There are important differences between static and dynamic simulators. Digestion is a dynamic process, and physico-chemical conditions, such as $\mathrm{pH}$, digestive enzyme concentrations, etc., occurring in the different compartments change with time. Static gastrointestinal simulators often use a single set of initial conditions for each part of the digestion and do not take into account the evolution of parameters with time [24,25]. To improve these conditions, several dynamic multi-compartmental simulators have been developed during the past decades.

Molly et al. [26] designed the first dynamic gastrointestinal simulator with the aim of emulating the different conditions of the digestive system of the human body and its interaction with the intestinal flora. This simulator (called SHIME) consisted of a multi-compartmental system made up of five serial stirred reactors simulating the duodenum/jejunum, ileum, cecum, and ascending colon, transverse colon, and descending colon. It also presented a sixth reactor to simulate the stomach. In addition, Minekus et al. [27] developed a multicompartmental in-vitro model that accurately reproduces the evolution of meal transit, $\mathrm{pH}$, and bile salt concentrations along the different gastrointestinal parts. Since the development of these two first dynamic gastrointestinal simulators, others have evolved over the years with the aim of studying infant digestion, simulating the microbial conditions in intestines, or testing the effects of several molecules, bacteria, or acids on the digestive tract of humans [28-32].

The aim of this work is to analyze the behavior of two very common types of microplastics (polyethylene and polypropylene) contaminated with metals (chromium and lead) along the digestive tract by means of in-vitro experiments using a membrane bioreactor system mimicking the human gastrointestinal tract conditions. This type of computer-controlled dynamic model is able to reproduce the physiological conditions of the human gastrointestinal tract and is normally used to study the 
effects of the active components of drugs and their resistance along the different phases of digestion. Nevertheless, the present work aims to demonstrate that it is also possible to study the bioaccessibility of the metal released from the microplastics in the human body using the gastrointestinal simulator, and this could serve as complementary and/or previous study to more complex and costly human intervention studies. To the best of the authors' knowledge, this is the first study that uses a dynamic gastrointestinal simulator to analyze the release of pollutants present in microplastics along the dynamic digestion process.

\section{Materials and Methods}

\subsection{Materials and Chemical Agents}

The choice of microplastics and contaminants was based on a previous study published by the same authors [14]. The results of that study demonstrated that $\mathrm{Cr}$ and $\mathrm{Pb}$ were the fastest adsorbed metals and in the greatest quantity, and that the microplastics showing the most favorable interactions with $\mathrm{Cr}$ and $\mathrm{Pb}$ were polyethylene (PE) and polypropylene (PP), respectively. Therefore, in accordance with those results, for the gastrointestinal simulator in this study, the metals chosen were $\mathrm{Cr}$ and $\mathrm{Pb}$, while the plastics were $\mathrm{PE}$ and $\mathrm{PP}$, which came from recycled pellets and commercial box waste, respectively. The plastic was shredded and sieved using a stainless-steel sieve with a mesh of $<5 \mathrm{~mm}$ in order to obtain a microplastic size. To prepare the metal solutions, standard solutions of $1000 \mathrm{mg} / \mathrm{L}$ were acquired from the Panreac brand for $\mathrm{Cr}$ and $\mathrm{Pb}$. The solutions were composed of chromium and lead nitrate in nitric acid $(0.5 \mathrm{M})$.

In order to simulate the presence of real food together with the assayed microplastics during the gastrointestinal simulation, uperized skimmed milk was used. To prepare the Salivary Simulated Fluid (henceforth referred to as SSF) and Gastric Simulated Fluid (henceforth referred to as GSF), corresponding to the gastric phase of digestion, the following reagents were used: Potassium Chloride $\left(\mathrm{KCl}, 99.5 \%\right.$ purity) from the brand Merck, Sodium Hydrogen Carbonate anhydrous $\left(\mathrm{NaHCO}_{3}\right.$, 99.5\% purity) from the brand Sigma-Aldrich, Potassium Dihydrogen Phosphate anhydrous $\left(\mathrm{KH}_{2} \mathrm{PO}_{4}\right.$, $99 \%$ purity), Sodium Chloride ( $\mathrm{NaCl}, 99 \%$ purity), Magnesium Chloride hexahydrate $\left(\mathrm{MgCl}_{2} \cdot 6 \mathrm{H}_{2} \mathrm{O}\right.$, $98 \%$ purity), Hydrochloric Acid (35\%), and Calcium Chloride dihydrate $\left(\mathrm{CaCl}_{2} \cdot 2 \mathrm{H}_{2} \mathrm{O}, 99 \%\right.$ purity), from the brand Panreac. Compositions of the SSF and GSF were adopted from Brodkorb et al. [33].

In order to simulate the conditions of the different phases of human digestion (gastric phase, duodenal phase, and intestinal absorption), different enzymes and salts were necessary, which are naturally secreted by the body. The enzymes and salts used in this study were as follows: Alpha-Amylase from human saliva, Pepsin from porcine gastric mucosa, Lipase from porcine pancreas, Pancreatin from porcine pancreas, Trypsin from bovine pancreas, Bile salts from Sigma-Aldrich, and Lipoid p45 from Lipoid GmbH.

\subsection{Methods}

\subsubsection{Contamination of Microplastics in Laboratory}

Solutions of both metals $(\mathrm{Cr}$ and $\mathrm{Pb})$ were prepared in Milli-Q water in order to contaminate the microplastics. Then, $100 \mathrm{~mL}$ of each mother solution were put into a glass beaker and, subsequently, $0.5 \mathrm{~g}$ of PE were added to the $\mathrm{Cr}$ solution and $0.5 \mathrm{~g}$ of $\mathrm{PP}$ to the $\mathrm{Pb}$ solution. These solutions were kept stirred in an orbital agitator Comecta Ivymen AG-200 at $160 \mathrm{rpm}$ for 14 days. This time was enough to reach equilibrium in the adsorption. At the end of this period, a sample of each solution was taken and metal concentration in liquid was measured using Inductively Coupled Plasma Mass (ICP-masses), with a mass spectrometer NexION 300D with ionization source by plasma torch and ion filter by quadrupole. Finally, the amount of metal retained by each type of plastic was determined using the following equation:

$$
q_{e}=\frac{C_{i}-C_{e}}{m \cdot V}
$$


where $q_{e}$ is the equilibrium adsorption capacity of each metal on the adsorbent $\left(\mathrm{mg} \mathrm{g}^{-1}\right) ; C_{i}$ is the initial concentration of the metal $\left(\mathrm{mg} \mathrm{L}^{-1}\right)$ in the aqueous phase; $C_{e}$ is the equilibrium concentration of each metal $\left(\mathrm{mg} \mathrm{L}^{-1}\right)$ in the aqueous phase; $\mathrm{m}$ is the mass of microplastic; and $\mathrm{V}$ is the sample volume $(L)$. During the experiment, a solution containing microplastics without contaminants was subjected to the same procedure and used as a blank. Likewise, a previous control test without plastics was carried out with metal solutions to check that there was no metal adsorption by the flasks and there was no precipitation of metals. The blank vials were subjected to the same procedure, and metal concentration in liquid was measured using ICP-masses.

Finally, the microplastics were separated from the solution by filtration with a vacuum pump using Filter-Lab 1240 cellulose filters with a pore size of 16-18 $\mu \mathrm{m}$. They were left to dry in an oven at a temperature of $40{ }^{\circ} \mathrm{C}$ for $24 \mathrm{~h}$. It is not recommended to dry the plastic at higher temperatures, as excessive heat can cause alterations in the polymer. After finishing the tests in the simulator, the microplastics were examined under a Portable Digital Microscope with $4 x$, with the objective of detecting possible alterations on the surface of the plastic.

\subsubsection{Gastrointestinal-Tract-Simulating Membrane Bioreactor (GITSMB)—SimuGIT}

The dynamic gastrointestinal simulator system used (SimuGIT) was developed by the Research Group TEP025 of the Department of Chemical Engineering of the University of Granada [31].

The dynamic in-vitro Gastrointestinal-Tract-Simulating Membrane Bioreactor GITSMB (SimuGIT), schematically shown in Figure 1, consists of a continuous stirred-tank reactor (CSTR) connected in series to a continuous plug-flow tubular reactor (PFTR) equipped with a monochannel tubular ceramic microfiltration membrane. The CSTR used to simulate the gastric digestion in the stomach is a benchtop fermenter supplied by Braun Biotech International (model Biostat B). It comprises a conventional autoclavable stirred tank glass vessel equipped with an impeller stirrer (180 W, model Rushton) and a proportional-integral-derivative (PID) unit control system for the temperature, level, foam, dissolved oxygen, and $\mathrm{pH}$. The control system unit includes an RS-422 interface that enables the control of the CSTR with a computer. The CSTR has an external jacket to maintain constant temperature, such that the temperature in the vessel is measured by means of a Pt-100 digital sensor and is accurately controlled (Tsetpoint $\pm 0.1^{\circ} \mathrm{C}$ ) by the PID loop connected to a thermostatic laboratory bath. The CSTR system also has sampling and reagent addition inlets by means of several peristaltic pumps (Eyela, modelMP-3). The $\mathrm{pH}$ inside the CSTR is measured by a pH electrode (Hamilton, model Easyferm Plus K8) immersed in the vessel and adjusted by an own-made $\mathrm{pH}$ control system based on data acquisition modules, which acts on two different peristaltic pumps that dose the acid and basic solutions ( $\mathrm{HCl}$ or $\mathrm{NaHCO}_{3}$ ).

The digested solution exiting the CSTR is continuously driven to the PFR. To this end, the PID control system acts on impulsion and return peristaltic pumps (two of the four peristaltic pumps integrated in the benchtop fermented, as previously described), such that by varying the flow rates of these pumps, it is possible to regulate the pressure inside the hydraulic circuits, as well as the product filtration rate. In addition to this own-developed control pressure mechanism, the operating pressure can be adjusted accurately (P setpoint $\pm 10 \mathrm{mmHg}$ ) with a spring-loaded pressure-regulating valve (SS-R4512MM-SP model, Swagelok) and monitored by a digital pressure gauge (Endress + Hauser, model Ceraphant PTC31).

The continuous PFR connected in series to the CSTR serves for the simulation of the conditions in the intestine. It consists of a cylindrical tube made of stainless steel (provided by Prozesstechnik $\mathrm{GmbH}$, Basel, Switzerland) equipped with a monochannel ceramic microfiltration (MF) membrane in tubular configuration provided by Atech Innovations $\mathrm{GmbH}$. The MF membrane used for the experiments is an inorganic one of $\alpha-\mathrm{Al}_{2} \mathrm{O}_{3}$ active surface with a mean pore diameter equal to $0.2 \mu \mathrm{m}$ and molecular weight cut-off in the range $1.2 \mathrm{kDa}$ (model $20 \mathrm{~N}$ ).

The dimensions of the selected membrane are $1000 \mathrm{~mm}$ in length, $6 \mathrm{~mm}$ in duct diameter, and $2 \pm 0.5 \mathrm{~mm}$ in thickness. This type of MF membrane also ensures a series of advantageous 
characteristics, such as high resistance to temperature (suitable for steam sterilization at $121^{\circ} \mathrm{C}$ ) and pressure (up to 10 bar) during the cleaning protocols, $\mathrm{pH}$ stability ( 0 to 14), possibility of back pulsing, very high abrasion resistance (against aggressive chemical reagents), optimal permeability recovery, as well as high selectivity and performance, and long lifetime service. The PFR is integrated with the CSTR by means of a drive and return system made of chemically resistant polyethylene tubes. Finally, a precision electronic mass balance with USB connectivity (Sartorius, model Quintix 5102, accuracy equal to $1 \mathrm{mg}$ ) is coupled to an automatic sampling and data registration system in order to register values of permeate (bioaccessible fraction that crossed the membrane) with time.

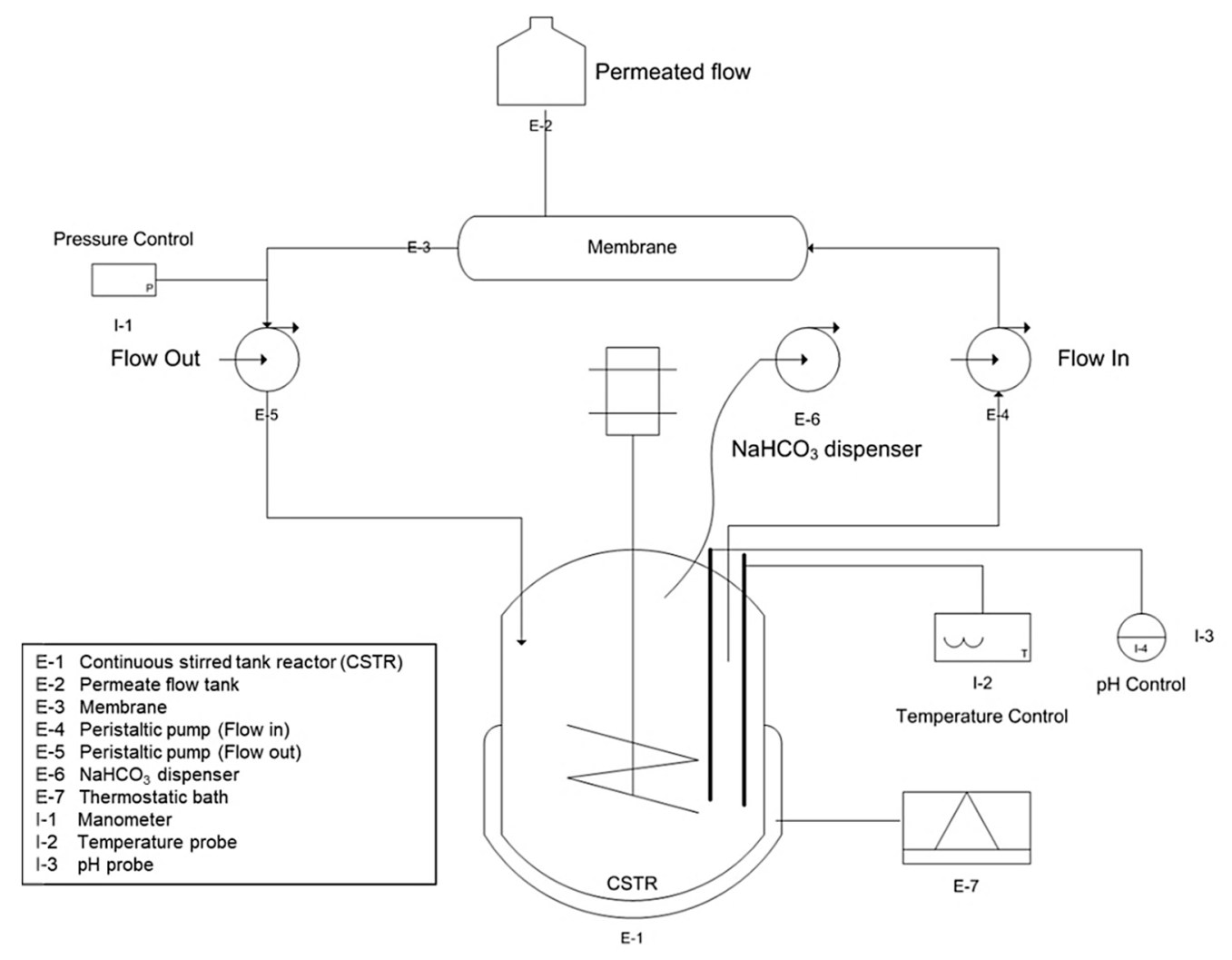

Figure 1. Flow diagram of the dynamic in-vitro Gastrointestinal-Tract-Simulating Membrane Bioreactor (SimuGIT).

\subsubsection{GITSMB Conditions}

- Gastric Phase

When the trial began, the bath temperature that keeps the reactor jacket warm was set at $37.5 \pm 1{ }^{\circ} \mathrm{C}$ throughout the process, and the reactor stirring speed was set at $50 \mathrm{rpm}$ to simulate the peristaltic movements of the stomach. Next, $800 \mathrm{~mL}$ of GSF and $14 \mathrm{~mL}$ of SSF were prepared using the reagents mentioned in Section 2.1. The concentrations used of each reagent for each fluid were pre-established in accordance with Brodkorb et al. [33]. Once prepared, the GSF was introduced into the reactor and heated to a temperature of $37.5^{\circ} \mathrm{C}$. At this point, the $\mathrm{pH}$ dropped to 3 , as the empty stomach was simulated before adding the food with the microplastics.

In parallel, $20 \mathrm{~g}$ of skimmed milk were weighed and $0.5 \mathrm{~g}$ of contaminated plastic were added. Since two different plastics ( $\mathrm{PE}-\mathrm{Cr}$ and $\mathrm{PP}-\mathrm{Pb}$ ) were chosen, two separate tests were carried out. The SSF was then mixed with the food preparation + microplastics; $1 \mathrm{~mL}$ alpha-amylase solution (75 U/mL), $0.1 \mathrm{~mL} \mathrm{CaCl} 2 \cdot 2 \mathrm{H}_{2} \mathrm{O}$ of concentration $0.3 \mathrm{M}$, and $4.9 \mathrm{~mL}$ distilled water were added (final salivary fluid to food preparation ratio of 1:1). The mixture was shaken for $2 \mathrm{~min}$ and the $\mathrm{pH}$ was adjusted to 7 (if necessary). 
Once the GSF was hot, the mixture of the food with the SSF was added to the reactor tank, stirred for a few seconds, and an initial sample was taken. Then, a $10 \mathrm{~mL}$ solution of pepsin (2000 U) and $50 \mathrm{mg}$ of phospholipid (Lipoid p45) were added, and the $\mathrm{pH}$ was adjusted to 3 by controlled dosing of $6 \mathrm{M} \mathrm{HCl}$. From this moment on, a sample was taken every $5 \mathrm{~min}$ for the next half-hour.

- Duodenum Phase

When the gastric phase ended with the last sample taken, the $\mathrm{pH}$ of the GSF was raised to 6.5 by dosing $1 \mathrm{M} \mathrm{NaHCO}_{3}$ at a rate of $2.05 \mathrm{~mL} / \mathrm{min}$ and a sample was taken after adjustment. This $\mathrm{pH}$ simulates the action of pancreatic juices on the food being digested. Intestinal enzymes were added: $10 \mathrm{~mL}$ solution of pancreatic lipase $(2000 \mathrm{U} / \mathrm{mL}$ ), biliary salts (for a final concentration of $5 \mathrm{mM}$ ), $10 \mathrm{~mL}$ solution of pancreatin (10\%), and $1 \mathrm{~mL}$ solution of trypsin $(50 \mathrm{mg} /$ assay). Digestion in the duodenum takes about $10 \mathrm{~min}$ after the addition of enzymes, and a sample was taken after that digestion period. The approximate total duration of this phase (including $\mathrm{pH}$ rise, addition of enzymes, and digestion) was $30 \mathrm{~min}$.

- Intestinal Absorption Phase

To simulate intestinal absorption, fluids from the bioreactor were pumped to flow through the modular filtration system described in Section 2.2.2. A $0.2 \mu \mathrm{m}$ membrane size was chosen for these trials, based on tests carried out previously [34,35]. The system overpressure limit was set at $50 \mathrm{mmHg}$, so that the diffusion of metals through the membrane was only due to passive transport. It is important to remind that the ionization characteristics of a compound can have a profound effect on the rate of its transfer by passive diffusion because only the unionized species are capable of passive diffusion across the membrane. Once the circuit was primed and fluids began to fall into the bioreactor, the intestinal absorption phase was considered to have begun and lasted $180 \mathrm{~min}$. Samples were taken at $30,60,90,120,150$, and $180 \mathrm{~min}$. Two samples were taken each time, one from the fluid filtrated through the membrane (permeate) and another from the retained fluid, which forms part of the colonic residue (retained).

In summary, each simulation test lasted approximately $4 \mathrm{~h}$ : Gastric phase ( $30 \mathrm{~min})$, duodenal phase (30 $\mathrm{min})$, and intestinal absorption phase (180 $\mathrm{min})$. Each trial was conducted in duplicate. Throughout the trial, the system program generated a data file in which all the events and processes that occurred during the simulation were recorded. This file was then processed in the computer to obtain information on all the variables.

\subsubsection{Analysis of the Samples}

All samples collected during the assay were refrigerated and, subsequently, the concentration of metal present in the fluids in each sample was measured using ICP-masses. The concepts of release or bioaccessibility and bioavailability were used in order to measure the amount of $\mathrm{Cr}$ and $\mathrm{Pb}$ released along the digestive tube that is present in the chymus and the amount absorbed by the membrane, respectively. The release corresponds to the metal fraction $(\mathrm{Cr}$ or $\mathrm{Pb})$ delivered by microplastics in the gastrointestinal tract during the gastric and duodenal phases, and was calculated using Equation (2), adapted from Rivas-Montoya et al. [31]. When release and precipitation processes took place simultaneously, the same equation was used to calculate the bioaccessible percentage as the released and non-precipitated fraction in the chymus. On the other hand, bioavailability corresponds to the metal fraction absorbed by diffusion through the membrane during the intestinal absorption phase, and was calculated using Equation (3), adapted from Ariza et al. [36]:

$$
\begin{gathered}
\text { Release or bioaccesibility }(\%)=\frac{\text { Metal amount in chymus }}{\text { Initial metal amount in plastic }} \times 100 \\
\text { Bioavailability }(\%)=\frac{\text { Metal amount in IAS }}{\text { Initial metal amount in plastic }} \times 100
\end{gathered}
$$


where IAS means intestinal absorption samples. In both equations, the amounts of metal present in the chymus and in the plastic are expressed in milligrams (mg).

\section{Results}

\subsection{Characterization of Microplastics after the In-Vitro Tests}

The main properties of the microplastics used (specific surface, porosity, pore size, and null point) were analyzed in a previous study by the same authors [14]. The specific surfaces of PP and PE are the largest of the five types of microplastics analyzed in that study ( 1.4 and $2.7 \mathrm{~m}^{2} / \mathrm{g}$, respectively). This influences the adsorption and desorption capacities due to the competition produced by the ions in the medium to occupy the holes in the plastic structure [37,38]. The pore volume of PE is larger than that of $\mathrm{PP}\left(40 \cdot 10^{-3}\right.$ and $30 \cdot 10^{-3} \mathrm{~cm}^{3} / \mathrm{g}$, respectively), while pore size is inversely proportional to volume, with PP having slightly larger pores than PE, although both have a pore size close to $40 \AA$.

The microplastics used were analyzed after the in-vitro tests using a digital microscope in order to detect possible surface degradation or deformation, as well as color changes produced after its passage through the different simulated gastrointestinal conditions (Figure 2). As can be observed, PP microplastics have suffered slight degradation at the edges and have also split a little, being smaller in size. However, the PE microplastics underwent further degradation after the test, which can be detected in a loss of the original color and shape of the microplastic, as well as great degradation of the particle edges (Figure $2 b$ ). The PE used came from recycled pellets in which different types of polyethylene are mixed (mainly high density and low density). Both types of polyethylene have different properties (e.g., density, crystallinity, chemical resistance, hardness, etc.) and different behavior in relation to the surrounding environment, which could have caused the degradation of PE to be greater than that of PP. However, the effect of these factors is complex and must be studied in depth in subsequent studies.

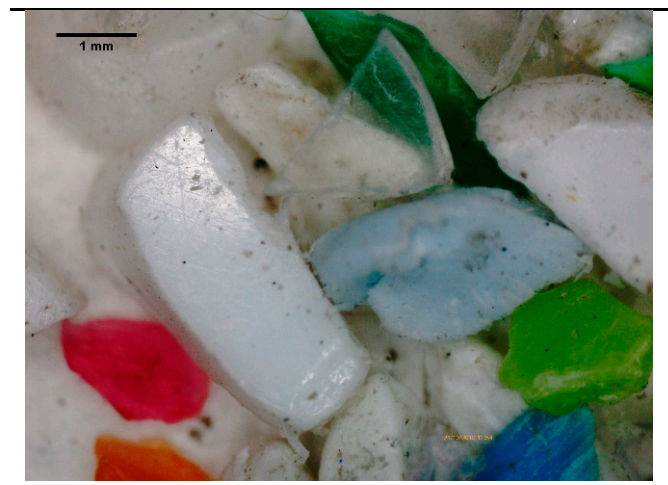

(a)

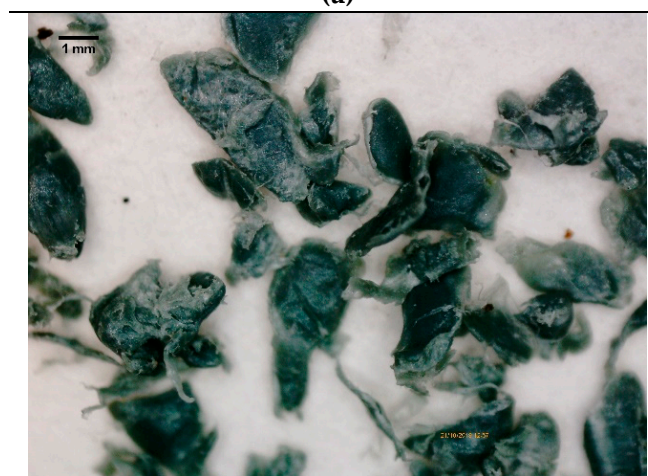

(c)

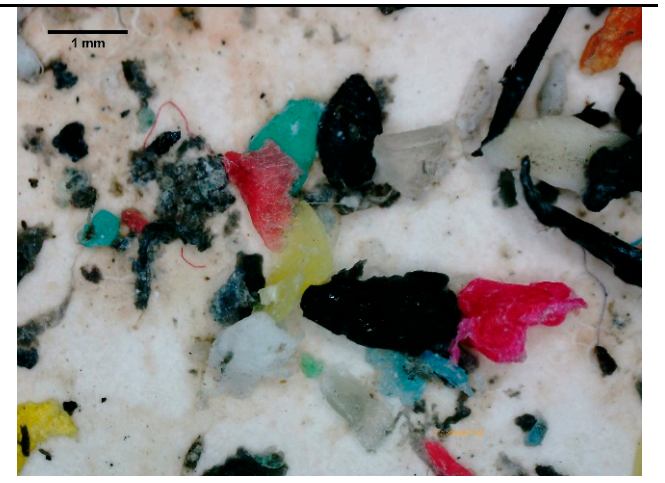

(b)

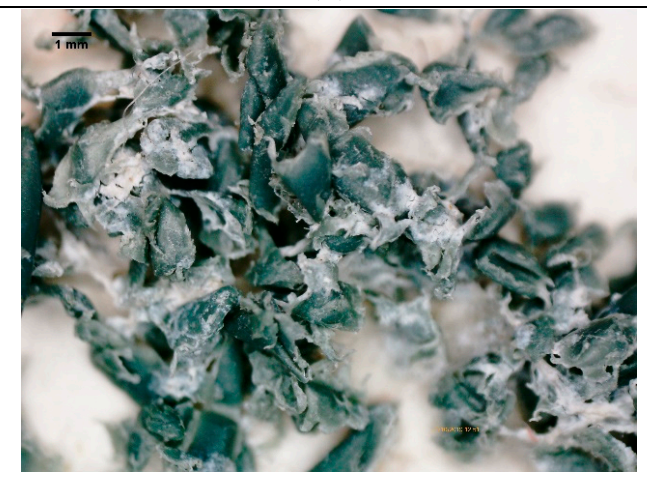

(d)

Figure 2. Photographs of the microplastics used in the in-vitro tests. (a) PP before the test; (b) PP after the test; (c) PE before the test; (d) PE after the test. 
This degradation may have led to the release of small fibers or nano-sized PE particles (known as nano-plastics). There are numerous factors that control the degradation of polymers, such as the type of chemical bond in the structure, the $\mathrm{pH}$ of the medium, the composition of the polymer, or the uptake of water [39]. According to this author, it is difficult to analyze the degradation of a polymer, since there are several indicators (e.g., loss of molecular weight, loss of mechanical strength, or release of monomers), and not all of these changes occur necessarily with the same kinetics. However, this author states that when polymers suffer erosion, morphological changes occur and a loss of surface material is produced. It is clear that the PE after the in-vitro test in the gastrointestinal simulator has undergone surface changes, so it is probable that a release of nano-fibers or nano-particles of PE into the gastrointestinal tract may have occurred.

For both types of microplastics used (PE and PP), the physical alteration suffered by the microplastics studied may influence the adsorption capacity and diffusivity of $\mathrm{Cr}$ and $\mathrm{Pb}$ through the structure [40].

\subsection{Metal Amount Adsorbed by Microplastics in the Previous Adsorption Tests}

Table 1 shows the results obtained for the $\mathrm{q}_{\mathrm{e}}$ measured at PE and PP according to the methodology described in Section 2.2.1. As can be observed, $\mathrm{PP}$ has a higher adsorption capacity for $\mathrm{Pb}$ than PE for $\mathrm{Cr}$, which is reflected in a higher $\mathrm{q}_{\mathrm{e}}$. Since the adsorption test was performed with $0.5 \mathrm{~g}$ of microplastics, the amount of metal present in these plastics is half of $\mathrm{q}_{\mathrm{e}}$. In view of the results obtained, there is more metal present in PP than in PE at the time of starting the in-vitro tests.

Table 1. Maximum calculated amount of metal that microplastics can adsorb $\left(\mathrm{q}_{\mathrm{e}}\right)$, and amount of metal contained in the plastics at the start of the in-vitro tests.

\begin{tabular}{ccc}
\hline Plastic and Metal & $\mathbf{q e}_{\mathbf{e}}\left(\mathbf{m g} \cdot \mathbf{g}^{\mathbf{- 1}}\right)$ & mg in microplastic \\
\hline $\mathrm{PE}-\mathrm{Cr}$ & 2.31 & 1.16 \\
$\mathrm{PP}-\mathrm{Pb}$ & 4.92 & 2.46 \\
\hline
\end{tabular}

The adsorption capacity of polymers is influenced by many variables that are not the main objective of this study. Some of these variables are the type of polymer and the type of contaminant with which polymers interact, since properties such as the point of zero charge (pzc) of the polymer, the surface groups, or the degree of degradation should be considered, as well as characteristics of the contaminant, such as polarity, hydrophobicity, or the speciation of the metal in aqueous solution (i.e., hydrated, in ionic form, in molecular form, etc.) [41-44]. In addition, the properties of the medium (especially the $\mathrm{pH}$ ) should also be taken into account.

\subsection{In-Vitro Simulating Assay PE-Cr}

The most noticeable result of the in-vitro simulating assay PE-Cr was that $86.08 \%$ of the initial $\mathrm{Cr}$ retained in the microplastics was released after two minutes of contact with the GSF fraction (Figure 3a). As a consequence, that $\mathrm{Cr}$ became bioaccessible at this point of the stomach simulating phase. This resulted in the release of $0.99 \mathrm{mg} \mathrm{Cr}$ into the GSF solution. However, from that moment on, the amount of $\mathrm{Cr}$ available in solution during the gastric phase began to decrease noticeably, so that at the end of this phase, only $0.38 \mathrm{mg}$ of $\mathrm{Cr}$ remained available in solution, and it is susceptible to reach the intestinal absorption phase. Therefore, the percentage of bioaccessible $\mathrm{Cr}$ decreased from $86.08 \%$ at minute 2 to $32.76 \%$ at minute 27, as can be seen in Figure 3a. These changes took place at a $\mathrm{pH}$ of approximately 3 (Figure $4 \mathrm{~A}$ ) and a temperature of $37.5^{\circ} \mathrm{C}$, values that remained almost constant throughout the entire gastric phase. This value of $\mathrm{pH}$ is related with the action of pepsin and phospholipid on the added uperized milk. 


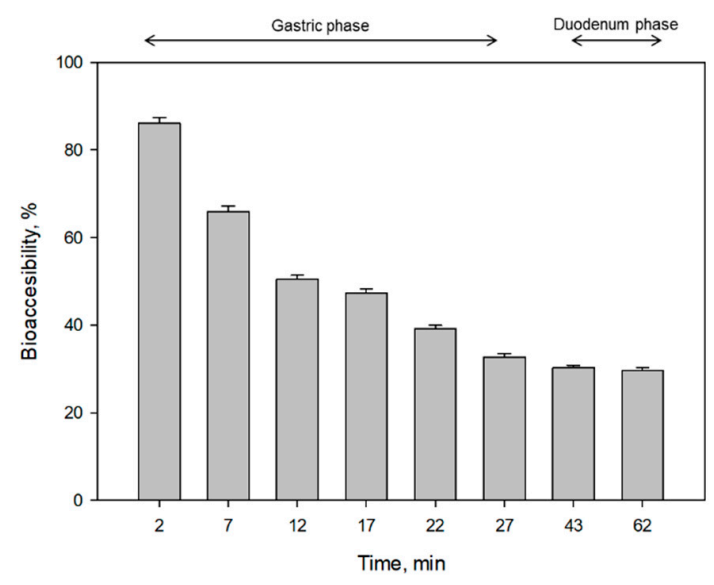

(a)

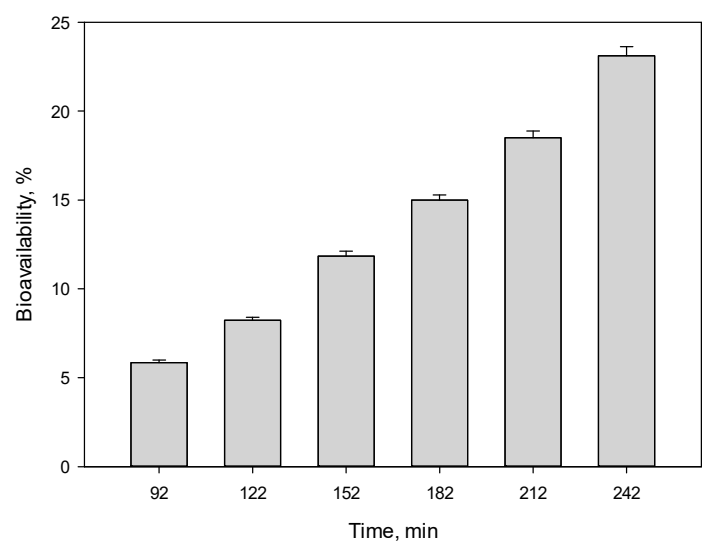

(b)

Figure 3. (a) Percentage of Cr available in the Gastric Simulated Fluid (GSF) during the gastric and duodenal phases (bioaccessibility); (b) percentage of $\mathrm{Cr}$ absorbed by the membrane during the intestinal absorption phase, with respect to the amount of $\mathrm{Cr}$ that was initially adsorbed onto the microplastic (bioavailability).

The fast release of $\mathrm{Cr}$ into the medium may be due to a chemical preference of metal for acids, already demonstrated by some studies [45]. Deitsch and Rockaway [46] suggested that intestinal surfactants increase the rate of diffusion of solutes present in the polymer. Bakir et al. [37] also performed desorption tests of persistent organic pollutants (POPs) contained in microplastics in seawater and in the presence of intestinal surfactants, establishing that the most favorable and rapid desorption occurred in the second case.

The rapid release of $\mathrm{Cr}$ might also be related to the characteristics of the chosen polymer. The PE used came from recycled pellets in which different types of polyethylene are mixed (mainly high density and low density). Both types of polyethylene have different properties (e.g., density, crystallinity, chemical resistance, hardness, etc.) and different behaviors in relation to the surrounding environment. In addition, PE has a high specific surface and a significant porosity, which enhance the adsorption of pollutants [12]. In addition, the degradation of the PE plastic surface during the assay can cause breakage of bonds and formation of cracks, favoring the diffusivity of the particles and, therefore, their rapid release into the medium [47].

$\mathrm{Cr}^{3+}$ in solution can form different complexes or can precipitate depending on the ions present in the medium, the $\mathrm{pH}$, and other factors (Gorny et al., [48]). Most researchers indicate the precipitation of $\mathrm{Cr}$ as hydroxide from pH 5-6 (Fendorf, [49]; Rai et al., [50]), although it can also precipitate as oxide, depending on the aqueous medium conditions.

Rai et al. [50] studied the solubility of $\mathrm{Cr}$ and its different species from hydrolysis reactions, and estimated that at $\mathrm{pH}$ values lower than $4, \mathrm{Cr}^{3+}$ precipitation was produced in the form of hydroxide, according to the following reaction:

$$
\begin{gathered}
\mathrm{Cr}^{3+}+3 \mathrm{H}_{2} \mathrm{O} \rightleftharpoons \mathrm{Cr}(\mathrm{OH})_{3}(\mathrm{~s})+3 \mathrm{H}^{+} \\
K_{s}=9.64 \pm 0.23
\end{gathered}
$$

As described in Section 2.1, numerous chemical compounds have been used in the tests of this study that provide a great diversity of cations and anions with which $\mathrm{Cr}^{3+}$ can interact to form various compounds in solution or precipitates (Figure S1, Supplementary Material). In this case, hydrated species and an oxide that precipitates from $\mathrm{pH} 4$ have been formed. Therefore, it can be concluded that, in this test, the precipitation of $\mathrm{Cr}$ occurs due to the interaction with the numerous species present in the medium. 


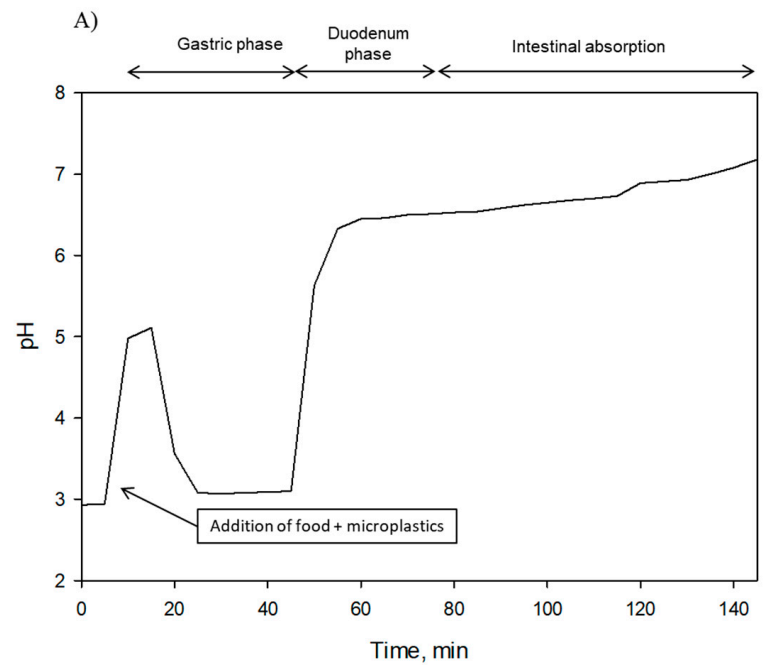

B)

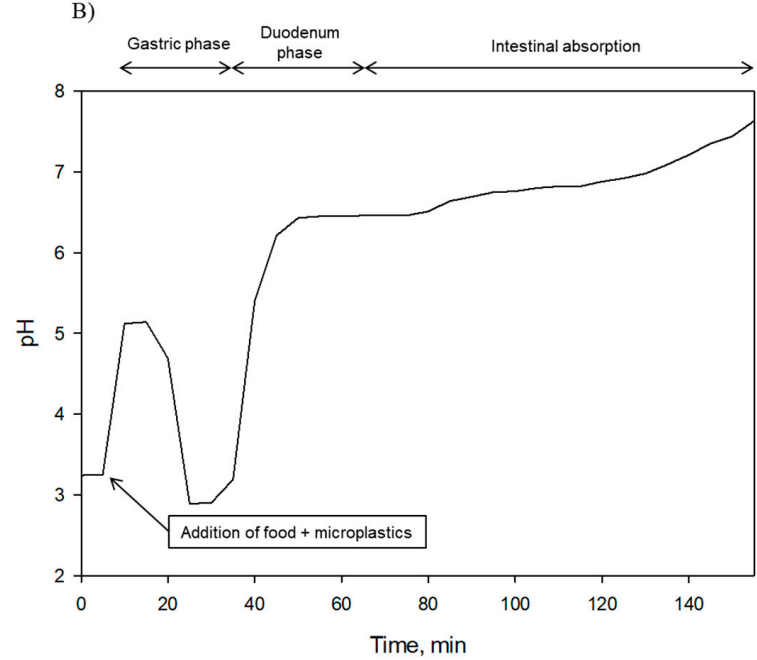

Figure 4. Evolution of $\mathrm{pH}$ along the three phases of the simulated digestion in the assays with (A) $\mathrm{Cr}$ and (B) $\mathrm{Pb}$.

According to Figure 3a, Cr started to precipitate after the first two minutes of contact with the GSF. This precipitate was therefore not available in the chyme at the beginning of the intestinal absorption phase. This precipitated $\mathrm{Cr}$ became part of the colonic residue (called "retained" in Section 2.2.3), a non-absorbed fluid that would pass into the colon and would eventually be excreted through urine and stool, as some studies have demonstrated [51]. Table 2 shows the amount of Cr precipitated at the end of gastric and duodenal phases, with respect to the maximum amount of $\mathrm{Cr}$ released by microplastics $(0.99 \mathrm{mg})$. The highest precipitation occurred during the gastric phase, in which more than $60 \%$ of the maximum $\mathrm{Cr}$ released was precipitated. By the end of the duodenal phase, $65 \%$ of the released $\mathrm{Cr}$ had precipitated, which means that this amount became part of the colonic residue. Therefore, $0.34 \mathrm{mg}$ of $\mathrm{Cr}$ remained bioavailable at the beginning of the intestinal absorption phase.

Table 2. Amount of $\mathrm{Cr}$ precipitated at the end of the gastric and duodenal phases and not available in the intestinal absorption phase.

\begin{tabular}{cccc}
\hline Phase & Time (min) & Milligrams of Cr Precipitated & \% of Cr Precipitated \\
\hline End of gastric phase & 27 & 0.62 & 61.98 \\
End of duodenal phase & 62 & 0.66 & 65.64 \\
\hline
\end{tabular}

${ }^{1} \mathrm{Cr}$ precipitated with respect to the maximum amount released from the microplastic. 
When the duodenal phase began, there was an increase in $\mathrm{pH}$ up to 6.5 (Figure 4) related to the addition of pancreatic juices. At this stage, the amount of $\mathrm{Cr}$ present in solution remained stable, and at the end, there was $29.58 \%$ of the initial $\mathrm{Cr}$ amount in the intestinal streams (Figure 3a), which was equivalent to $0.34 \mathrm{mg}$. This amount was available in the liquid when the intestinal absorption phase began, and could therefore be absorbed by the membrane. As the intestinal phase progressed, the amount of $\mathrm{Cr}$ permeating the membrane increased. When the intestinal absorption stage ended, $23.11 \%$ of the initial amount of $\mathrm{Cr}$ had been absorbed by the membrane (Figure $3 \mathrm{~b}$ ), which was equivalent to $0.23 \mathrm{mg}$.

\subsection{In-Vitro Simulating Assay PP-Pb}

In this test, $\mathrm{Pb}$ was released more slowly and gradually than $\mathrm{Cr}$. The maximum amount released to the gastrointestinal system occurred within $20 \mathrm{~min}$ of the start of the assay, with $32.41 \%$ of the initial $\mathrm{Pb}$ released (Figure $5 \mathrm{a}$ ). This was equivalent to $0.80 \mathrm{mg}$ of $\mathrm{Pb}$ available in GSF. As other studies have shown, $\mathrm{Pb}$ was released quite well at acid $\mathrm{pH}$, in media such as organic acids or nitric acid [52,53].

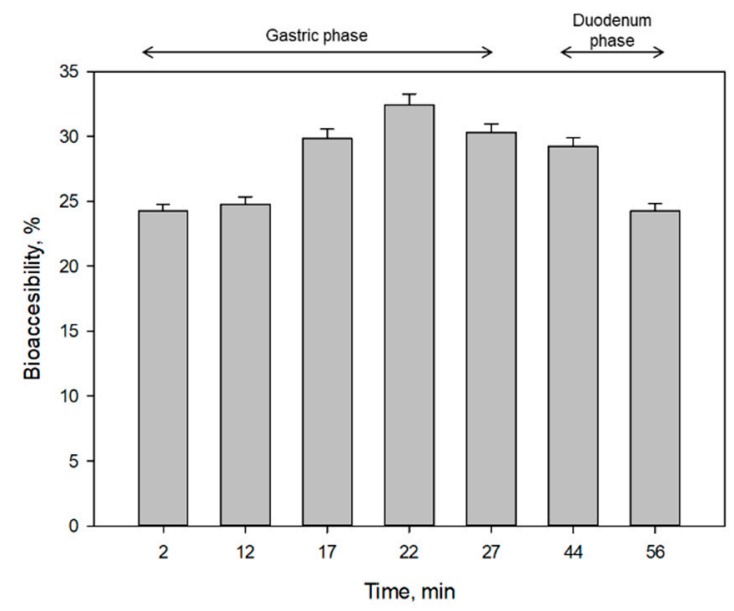

(a)

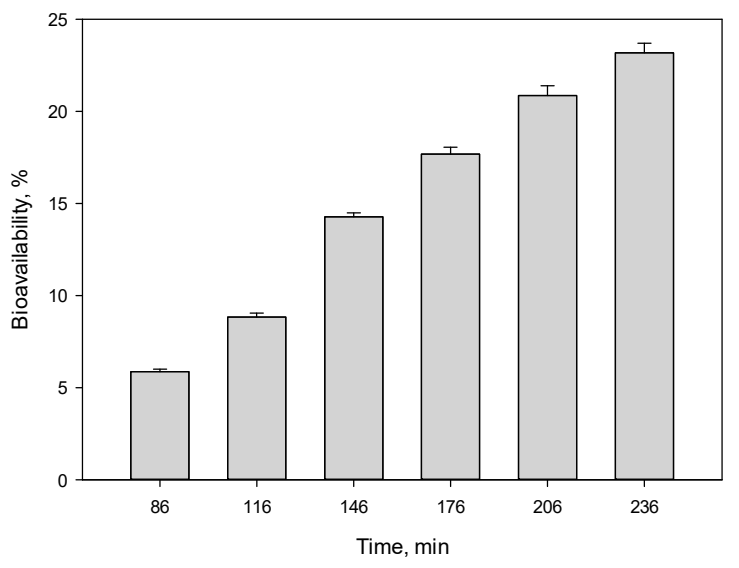

(b)

Figure 5. (a) Percentage of $\mathrm{Pb}$ available in the GSF during the gastric and duodenal phases (bioaccessibility); (b) percentage of $\mathrm{Pb}$ absorbed by the membrane during the intestinal absorption phase, with respect to the amount of $\mathrm{Pb}$ that was initially adsorbed onto the microplastic (bioavailability).

Compared to the results obtained in the PE-Cr test, $\mathrm{Pb}$ took longer to break free from microplastics and was also released in much smaller quantities. This could be due to a combination between the structure of $\mathrm{PP}$ and the chemical character of $\mathrm{Pb}$ that causes a stronger bond than that of $\mathrm{Cr}$ atoms with PE. According to Holmes [13], the most favorable interactions between metals and microplastics occur with bivalent cations, such as $\mathrm{Pb}^{2+}, \mathrm{Cd}^{2+}$, or $\mathrm{Cu}^{2+}$. Likewise, the previous adsorption study carried out by the same authors [12] demonstrated the existence of titanium oxide in PP microplastics, an inorganic pigment widely used in the manufacture of plastics [54]. This pigment can act by favoring the adsorption and retention of metals by contributing to the formation of negatively charged surfaces, which have more affinity for cations [55].

PP also has a specific surface lower than PE $\left(1.4 \mathrm{~m}^{2} / \mathrm{g}\right)$ and a moderate porosity $\left(30 \cdot 10^{-3} \mathrm{~m}^{3} / \mathrm{g}\right)$, which can also be decisive factors for slow release, as a large atom such as $\mathrm{Pb}$ can become very embedded in the pores of PP and have a slow diffusivity [56]. The release occurred during the gastric phase, at a pH close to 3 (Figure 4B) and a temperature close to $37.5^{\circ} \mathrm{C}$. These values remained constant throughout the gastric phase. As can be observed, the $\mathrm{pH}$ and temperature values showed the same behavior as in the test with $\mathrm{Cr}$. 
From that moment on, there was a slow and progressive decrease in the amount of $\mathrm{Pb}$ available in the liquid. This decrease could be associated with the rise in $\mathrm{pH}$ that occurred at the beginning of the duodenal phase as a result of the addition of pancreatic juices (Figure $4 \mathrm{~B}$ ). When the $\mathrm{pH}$ increases above $6, \mathrm{~Pb}^{2+}$ reacts with the carbonate ions $\left(\mathrm{CO}_{3}{ }^{2-}\right)$ available in the medium and precipitates in the form of lead hydroxycarbonate, also known as hydrocerusite, according to the following reaction [57]:

$$
3 \mathrm{~Pb}^{2+}+4 \mathrm{H}_{2} \mathrm{O}+2 \mathrm{CO}_{2} \rightleftharpoons \mathrm{Pb}_{3}\left(\mathrm{CO}_{3}\right)_{2}(\mathrm{OH})_{2}+6 \mathrm{H}^{+}
$$

$\mathrm{Pb}$ precipitation showed a very different behavior from that of $\mathrm{Cr}$. Table 3 shows the amount of $\mathrm{Pb}$ precipitated at the end of the gastric and duodenal phases. Of the maximum amount of $\mathrm{Pb}$ released by microplastics $(0.80 \mathrm{mg})$, more than $25 \%$ precipitated before the intestinal absorption phase (Table 3). In addition, precipitation began at the beginning of the duodenal phase (Figure 5a) when the $\mathrm{pH}$ increased to 6.5 (Figure 4B). This means that $0.20 \mathrm{mg}$ of the maximum $\mathrm{Pb}$ released became part of the colonic residue, which could later be excreted, according to some studies already conducted on the presence of $\mathrm{Pb}$ in the human body [58]. Thus, at the beginning of the intestinal absorption phase, $0.60 \mathrm{mg}$ of $\mathrm{Pb}$ was available to be permeated by the membrane.

Table 3. Amount of $\mathrm{Pb}$ precipitated at the end of the gastric and duodenal phases and not available in the intestinal absorption phase.

\begin{tabular}{cccc}
\hline Phase & Time (min) & Milligrams of Pb Precipitated & 1 \\
\hline End of gastric phase & 27 & 0.053 & 6.61 \\
End of duodenal phase & 56 & 0.20 & 25.22 \\
\hline${ }^{1} \mathrm{~Pb}$ precipitated respect to the maximum amount released from the microplastics.
\end{tabular}

When the intestinal absorption phase began, the $24.24 \%$ of the total initial $\mathrm{Pb}$ was available in postduodenal fluids that could consequently be absorbed by the membrane (equivalent to $0.60 \mathrm{mg}$ of $\mathrm{Pb}$ ). The behavior of absorption during that phase was very similar to that of $\mathrm{Cr}$ (Figure $5 \mathrm{~b}$ ), although $\mathrm{Pb}$ was absorbed in greater quantity by the membrane. Thus, when the intestinal absorption stage ended, $23.17 \%$ of the total initial $\mathrm{Pb}$ present in the microplastics had been absorbed by the membrane (Figure $5 \mathrm{~b}$ ), which was equivalent to $0.57 \mathrm{mg}$. Therefore, comparing both assays conducted, the reactor membrane simulating intestinal absorption absorbed more $\mathrm{Pb}$ than $\mathrm{Cr}$, in terms of net amounts ( 0.23 and $0.57 \mathrm{mg}$ absorbed for $\mathrm{Cr}$ and $\mathrm{Pb}$, respectively).

\subsection{Evolution of $\mathrm{pH}$, Temperature, and Pressure along the Assays}

The evolution of $\mathrm{pH}$, temperature, and pressure was quite similar in both the $\mathrm{PE}-\mathrm{Cr}$ and $\mathrm{PP}-\mathrm{Pb}$ assays. As for $\mathrm{pH}$ values, after adding the GSF, an empty stomach of a healthy adult was simulated and the $\mathrm{pH}$ dropped to values close to 3 . Then, after adding the skimmed milk with the microplastics and SSF, the $\mathrm{pH}$ increased to values close to 5 (Figure 4). At this point, the $\mathrm{pH}$ was lowered by adding $\mathrm{HCl} 6 \mathrm{M}$ until it reached a value close to 3, simulating GSF action on food, in which it was maintained during the whole gastric phase.

When the duodenal phase began, the $\mathrm{pH}$ was raised again by adding $\mathrm{NaHCO}_{3}$ at a rate of $2.05 \mathrm{~mL} \cdot \mathrm{min}^{-1}$ until reaching a value of 6.5 , simulating the passage of food with GSF and microplastics through the duodenum. Subsequently, with the addition of lipase and bile salts, the $\mathrm{pH}$ began to rise slowly during the intestinal absorption phase, until reaching values close to 7.5 , according to scientific literature that establishes a $\mathrm{pH}$ of 7.5 in the ileum [59]. The temperature was monitored throughout the duration of the trials, and no significant changes were observed, always remaining constant around 37.5 degrees. This indicates that the dynamic gastrointestinal simulator worked adequately, as the temperature during the whole digestion process is constant and should not vary.

As for the pressure, it was accurately controlled by the PID control system through the action of impulsion and return peristaltic pumps to maintain the pressure at $50 \mathrm{mmHg}$ during the trials. This pressure reliably simulates the real physiological pressure of the intestine inside the human 
body $[60,61]$. A very slight pressure similar to the minimum physiological pressure was applied so that the diffusion of metals was carried out only by passive diffusion. The difference in concentration is the only driving force in passive diffusion, and, therefore, bioaccessibility is due solely to the ability of each element to pass through the membrane. On the other hand, the interaction of $\mathrm{Cr}$ and $\mathrm{Pb}$ during the simulation and the formation of different species by effect of the conditions of the environment limit and affect their diffusion capacity through the membrane and, therefore, their bioaccessibility.

\section{Conclusions}

The objective of this research was to study the bioaccessibility of two heavy metals $(\mathrm{Cr}$ and $\mathrm{Pb})$ contained in microplastics in the human body by using a dynamic gastrointestinal simulator. This type of dynamic simulator is able to reproduce the physiological conditions of the human gastrointestinal tract and is normally used to study the effects of the active components of drugs and their resistance along the different phases of digestion. However, to the best of the authors' knowledge, this is the first study that used a dynamic gastrointestinal simulator to analyze the release of contaminants present in microplastics inside the human body.

The results obtained showed very different behaviors for both types of polymers and metals. With respect to metals, $\mathrm{Cr}$ was released very quickly into the stomach and began to precipitate within a few minutes, while $\mathrm{Pb}$ was released more slowly and in a smaller amount than $\mathrm{Cr}$, and started to precipitate when the $\mathrm{pH}$ increased to $6.5 \mathrm{in}$ the duodenum. A maximum amount of 0.99 and $0.80 \mathrm{mg}$ of $\mathrm{Cr}$ and $\mathrm{Pb}$, respectively, was released into the GSF, which was equivalent to $86.08 \%$ and $32.41 \%$ of the initial $\mathrm{Cr}$ and $\mathrm{Pb}$ adsorbed in microplastics, respectively. When the duodenal phase ended, $29.58 \%$ and $24.24 \%$ of the initial $\mathrm{Cr}$ and $\mathrm{Pb}$ amounts in microplastics, respectively, reached the intestinal absorption phase. At the end of that phase, more $\mathrm{Pb}$ than $\mathrm{Cr}(0.57$ and $0.23 \mathrm{mg}$, respectively) was absorbed by the reactor membrane simulating intestinal absorption. This represents $23.17 \%$ and $23.11 \%$ of the initial $\mathrm{Pb}$ and $\mathrm{Cr}$ amounts adsorbed onto microplastics, respectively. The type of polymer and its properties also influenced these behaviors. Properties such as great specific surface and porosity or the surface wear suffered by the microplastics during the assays could influence the diffusion of $\mathrm{Cr}$ and $\mathrm{Pb}$.

It is a reality that humans ingest microplastics or some of their components from various sources on a daily basis. These microplastics are usually contaminated with other substances from the external environment or with their own additives, and, inside of the human body, can produce the release of numerous substances that, even in small concentrations, can cause effects related to the appearance of some chronic illnesses or discomforts. The use of the dynamic gastrointestinal simulator to study the behavior of microplastics and their associated contaminants has proven in this study to be useful and reproducible. For this reason, future studies should focus on this field, and the effects that these substances can cause could be known with greater certainty.

Supplementary Materials: The following are available online at http://www.mdpi.com/2071-1050/12/11/4792/s1, Figure S1: Solubility diagram of $\mathrm{Cr}^{3+}$ at $25^{\circ} \mathrm{C}$ in the presence of compounds forming part of GSF in the in-vitro tests. This species diagram relates the molar fraction of each species as a function of $\mathrm{pH}$. The blue line indicates a chemical complex.

Author Contributions: Conceptualization, A.M.-F., M.Á.M.-L. and M.C.; Methodology, A.M.-F., M.Á.M.-L. and M.C.; Software, A.M.-F. and J.A.V.-P.; Validation, A.M.-F. and M.C.; Formal analysis, V.G. and J.A.V.-P.; Investigation, V.G., J.A.V.-P., M.Á.M.-L. and G.B.; Resources, A.M.-F. and G.B.; Data curation, V.G. and M.C.; Writing—original draft, V.G.; Writing—review and editing, M.Á.M.-L. and A.M.-F.; Visualization, V.G. and A.M.-F.; Supervision, A.M.-F., M.Á.M.-L., M.C., and G.B.; Project administration, A.M.-F., M.Á.M.-L., M.C. and G.B.; Funding Acquisition, A.M.-F., M.Á.M.-L., M.C. and G.B. All authors have read and agreed to the published version of the manuscript.

Funding: This research received no external funding.

Conflicts of Interest: The authors declare no conflict of interest. 


\section{References}

1. Cole, M.; Lindeque, P.; Halsband, C.; Galloway, T.S. Microplastics as contaminants in the marine environment: A review. Mar. Pollut. Bull. 2011, 62, 2588-2597. [CrossRef] [PubMed]

2. De Falco, F.; Gullo, M.P.; Gentile, G.; Di Pace, E.; Cocca, M.; Gelabert, L.; Brouta-Agnésa, M.; Rovira, A.; Escudero, R.; Villalba, R.; et al. Evaluation of microplastic release caused by textile washing processes of synthetic fabrics. Environ. Pollut. 2018, 236, 916-925. [CrossRef] [PubMed]

3. Sommer, F.; Dietze, V.; Baum, A.; Sauer, J.; Gilge, S.; Maschowski, C.; Gieré, R. Tire Abrasion as a Major Source of Microplastics in the Environment. Aerosol Air Qual. Res. 2018, 18, 2014-2028. [CrossRef]

4. Shahul Hamid, F.; Bhatti, M.S.; Anuar, N.; Anuar, N.; Mohan, P.; Periathamby, A. Worldwide distribution and abundance of microplastic: How dire is the situation? Waste Manag. Res. 2018, 36, 873-897. [CrossRef] [PubMed]

5. Frias, J.P.G.L.; Nash, R. Microplastics: Finding a consensus on the definition. Mar. Pollut. Bull. 2019, 138, 145-147. [CrossRef] [PubMed]

6. Bergmann, M.; Mützel, S.; Primpke, S.; Tekman, M.B. White and wonderful? Microplastics prevail in snow from the Alps to the Arctic. Sci. Adv. 2019, 5. [CrossRef] [PubMed]

7. Allen, S.; Allen, D.; Phoenix, V.R.; Le Roux, G.; Jiménez, P.D.; Simonneau, A.; Binet, S.; Galop, D. Atmospheric transport and deposition of microplastics in a remote mountain catchment. Nat. Geosci. 2019, 12, 339-344. [CrossRef]

8. Dris, R.; Gasperi, J.; Tassin, B. Sources and Fate of Microplastics in Urban Areas: A Focus on Paris Megacity. In Freshwater Microplastics-The Handbook of Environmental Chemistry; Wagner, M., Lambert, S., Eds.; Springer: New York, NY, USA, 2018; p. 69. Available online: http://www.springer.com/series/698 (accessed on 14 April 2020).

9. Rochman, C.M.; Hoh, E.; Kurobe, T.; The, S.J. Ingested plastic transfers hazardous chemicals to fish and induces hepatic stress. Sci. Rep. 2013, 3, 3263. [CrossRef]

10. Karbalaei, S.; Hanachi, P.; Walker, T.R.; Cole, M. Occurrence, sources, human health impacts and mitigation of microplastic pollution. Environ. Sci. Pollut. Res. 2018, 25, 36046-36063. [CrossRef]

11. Ashton, K.; Holmes, L.; Turner, A. Association of metals with plastic production pellets in the marine environment. Mar. Pollut. Bull. 2010, 60, 2050-2055. [CrossRef]

12. Brennecke, D.; Duarte, B.; Paiva, F.; Caçador, I.; Canning-Clode, J. Microplastics as vector for heavy metal contamination from the marine environment. Estuar. Coast Shelf Sci. 2016, 178, 189-195. [CrossRef]

13. Holmes, L. Interactions of Trace Metals with Plastic Production Pellets in the Marine Environment; University of Plymouth: Plymouth, UK, 2013.

14. Godoy, V.; Blázquez, G.; Calero, M.; Quesada, L.; Martín-Lara, M.A. The potential of microplastics as carriers of metals. Environ. Pollut. 2019, 255. [CrossRef] [PubMed]

15. Lusher, A. Microplastics in the Marine Environment: Distribution, Interactions and Effects. In Marine Anthropogenic Litter; Bergmann, M., Gutow, L., Klages, M., Eds.; Springer: New York, NY, USA, 2015; pp. 245-307.

16. Novotna, K.; Cermakova, L.; Pivokonska, L.; Cajthaml, T.; Pivokonsky, M. Microplastics in drinking water treatment-Current knowledge and research needs. Sci. Total Environ. 2019, 667, 730-740. [CrossRef] [PubMed]

17. Cox, K.D.; Covernton, G.A.; Davies, H.L.; Dower, J.F.; Juanes, F.; Dudas, S.E. Human Consumption of Microplastics. Environ. Sci. Technol. 2019, 53, 7068-7074. [CrossRef]

18. Ma, P.; Wei Wang, M.; Liu, H.; Feng Chen, Y.; Xia, J. Research on ecotoxicology of microplastics on freshwater aquatic organisms. Environ. Pollut. Bioavailab. 2019, 31, 131-137. [CrossRef]

19. Schwabl, P.; Köppel, S.; Königshofer, P.; Bucsics, T.; Trauner, M.; Reiberger, T.; Liebmann, B. Detection of Various Microplastics in Human Stool: A Prospective Case Series. Ann. Intern. Med. 2019, 171, 453. [CrossRef]

20. Liao, Y.; Yang, J. Science of the Total Environment Microplastic serves as a potential vector for $\mathrm{Cr}$ in an in-vitro human digestive model. Sci. Total Environ. 2020, 703, 134805. [CrossRef]

21. Campanale, C.; Massarelli, C.; Savino, I.; Locaputo, V. A Detailed Review Study on Potential Effects of Microplastics and Additives of Concern on Human Health. Int. J. Environ. Res. Public Health 2020, 17, 1212. [CrossRef] 
22. Cima, F. Tin: Environmental Pollution and Health Effects. In Reference Module in Earth Systems and Environmental Sciences; Elsevier: Amsterdam, The Netherlands, 2011; pp. 351-359. [CrossRef]

23. Darbre, P.D. Metalloestrogens: An emerging class of inorganic xenoestrogens with potential to add to the oestrogenic burden of the human breast. J. Appl. Toxicol. 2006, 26, 191-197. [CrossRef] [PubMed]

24. Dupont, D.; Mackie, A.R. Static and dynamic in vitro digestion models to study proteins stability in the gastrointestinal tract. Drug Discov. Today Dis. Model. 2016, 17-18, 23-27. [CrossRef]

25. Thuenemann, E.C. Dynamic Digestion Models: General Introduction. In The Impact of Food Bio-Actives on Gut Health; Verhoeckx, K., Ed.; Springer: Cham, Switzerland, 2015; pp. 33-36. [CrossRef]

26. Molly, K.; Woestyne MVande Smet IDe Verstraete, W. Validation of the simulator of the human intestinal microbial ecosystem (SHIME) reactor using microorganism-associated activities. Microb. Ecol. Health Dis. 1994, 7, 191-200. [CrossRef]

27. Minekus, M.; Marteau, P.; Havenaar, R. Multicompartmental dynamic computer-controlled model simulating stomach and small intestine. Altern. Lab. Anim. 1995, 23, 197-209.

28. Barroso, E.; Cueva, C.; Peláez, C.; Martínez-Cuesta, M.C.; Requena, T. Development of human colonic microbiota in the computer-controlled dynamic SIMulator of the GastroIntestinal tract SIMGI. LWT Food Sci. Technol. 2015, 61, 283-289. [CrossRef]

29. Ménard, O.; Cattenoz, T.; Guillemin, H.; Souchon, I.; Deglaire, A.; Dupont, D.; Picque, D. Validation of a new in vitro dynamic system to simulate infant digestion. Food Chem. 2014, 145, 1039-1045. [CrossRef]

30. Mainville, I.; Arcand, Y.; Farnworth, E.R. A dynamic model that simulates the human upper gastrointestinal tract for the study of probiotics. Int. J. Food Microbiol. 2005, 99, 287-296. [CrossRef] [PubMed]

31. Rivas-Montoya, E.; Ochando-Pulido, J.M.; López-Romero, J.M.; Martinez-Ferez, A. Application of a novel gastrointestinal tract simulator system based on a membrane bioreactor (SimuGIT) to study the stomach tolerance and effective delivery enhancement of nanoencapsulated macelignan. Chem. Eng. Sci. 2016, 140, 104-113. [CrossRef]

32. Sumeri, I. The Study of Probiotic Bacteria in Human Gastrointestinal Tract Simulator. In Competence Center of Food and Fermentation Technologies; TUT Press: Toyohashi, Japan, 2011.

33. Brodkorb, A.; Egger, L.; Alminger, M.; Alvito, P.; Assunção, R.; Ballance, S.; Bohn, T.; Bourlieu-Lacanal, C.; Boutrou, R.; Carrière, F.; et al. INFOGEST static in vitro simulation of gastrointestinal food digestion. Nat. Protoc. 2019, 14, 991-1014. [CrossRef]

34. Abad, P.; Arroyo-Manzanares, N.; García-Campa, A.M.; Martinez-Ferez, A. Effects of different vehiculization strategies for the allium derivative propyl propane thiosulfonate during dynamic simulation of the pig gastrointestinal tract. Can. J. Anim. Sci. 2019, 99, 244-253. [CrossRef]

35. González, E.; Gómez-Caravaca, A.M.; Giménez, B.; Cebrián, R.; Maqueda, M.; Martinez-Ferez, A.; Segura-Carretero, A.; Robert, P. Evolution of the phenolic compounds profile of olive leaf extract encapsulated by spray-drying during in vitro gastrointestinal digestion. Food Chem. 2018, 279, 40-48. [CrossRef]

36. Ariza, M.T.; Rodríguez, P.R.; Cervantes, L.; Soria, C.; Martínez-Ferri, E.; González-Barreiro, C.; Cancho-Grande, B.; Battino, M.; Simal-Gandara, J. Bioaccessibility and potential bioavailability of phenolic compounds from achenes as a new target for strawberry breeding programs. Food Chem. 2018, 248, 155-165. [CrossRef]

37. Bakir, A.; Rowland, S.J.; Thompson, R.C. Transport of persistent organic pollutants by microplastics in estuarine conditions. Estuar. Coast Shelf Sci. 2014, 140, 14-21. [CrossRef]

38. Rochman, C.M.; Hentschel, B.T.; The, S.J. Long-term sorption of metals is similar among plastic types: Implications for plastic debris in aquatic environments. PLoS ONE 2014, 9. [CrossRef] [PubMed]

39. Göpferich, A. Mechanisms of polymer degradation and erosion. Biomaterials 1996, 17, 103-114. [CrossRef]

40. Holmes, L.A.; Turner, A.; Thompson, R.C. Interactions between trace metals and plastic production pellets under estuarine conditions. Mar. Chem. 2014, 167, 25-32. [CrossRef]

41. Abu-zurayk, R.A.; Al, R.Z.; Hamadneh, I.; Al-dujaili, A.H. Adsorption of Pb (II), Cr (III) and Cr (VI) from aqueous solution by surfactant-modified diatomaceous earth: Equilibrium, kinetic and thermodynamic modeling studies. Int. J. Miner. Process. 2015, 140, 79-87. [CrossRef]

42. Zhang, W.; Zhang, L.; Hua, T.; Li, Y.; Zhou, X. The mechanism for adsorption of Cr (VI) ions by PE microplastics in ternary system of natural water environment. Environ. Pollut. 2019, 113440. [CrossRef]

43. Alemu, A.; Lemma, B.; Gabbiye, N. Adsorption of chromium (III) from aqueous solution using vesicular basalt rock. Cogent. Environ. Sci. 2019, 5. [CrossRef] 
44. Turner, A.; Holmes, L.A. Adsorption of trace metals by microplastic pellets in fresh water. Environ. Chem. 2015, 12, 600-610. [CrossRef]

45. Qiang, T.; Fan, G.; Yufeng, G.; Toru, I.; Takeshi, K. Desorption characteristics of Cr (III), Mn (II), and Ni (II) in contaminated soil using citric acid and citric acid-containing wastewater. Soils Found 2018, 58, 50-64. [CrossRef]

46. Deitsch, J.J.; Rockaway, E.J. Surfactant-Enhanced Desorption of Organic Pollutants from Natural Soil. In Physicochemical Groundwater Remediation; Springer: Boston, MA, USA, 2001; Volume 217, pp. 217-243.

47. Hartmann, N.B.; Rist, S.; Bodin, J.; Jensen, L.H.S.; Schmidt, S.N.; Mayer, P.; Meibom, A.; Baun, A. Microplastics as vectors for environmental contaminants: Exploring sorption, desorption, and transfer to biota. Integr. Environ. Assess. Manag. 2017, 13, 488-493. [CrossRef]

48. Gorny, J.; Billon, G.; Noiriel, C.; Dumoulin, D.; Lesven, L.; Madé, B. Chromium behavior in aquatic environments: A review. Environ. Rev. 2016, 24, 503-516. [CrossRef]

49. Fendorf, S.E. Surface reactions of chromium in soils and waters. Geoderma 1995, 67, 55-71. [CrossRef]

50. Rai, D.; Sass, B.M.; Moore, D.A. Chromium (III) hydrolysis constants and solubility of chromium (III) hydroxide. Inorg. Chem. 1987, 26, 345-349. [CrossRef]

51. Alvarado-Gámez, A.; Blanco-Sáenz, R.; Mora-Morales, E. El cromo como elemento esencial en los humanos. Rev. Costarric. Cienc. Méd. 2002, 23, 55-68.

52. Yang, J.Y.; Yang, X.E.; He, Z.L.; Li, T.Q.; Shentu, J.L.; Stoffella, P.J. Effects of pH, organic acids, and inorganic ions on lead desorption from soils. Environ. Pollut. 2006, 143, 9-15. [CrossRef] [PubMed]

53. Deng, L.; Su, Y.; Su, H.; Wang, X.; Zhu, X. Sorption and desorption of lead (II) from wastewater by green algae Cladophora fascicularis. J. Hazard. Mater. 2007, 143, 220-225. [CrossRef]

54. Hahladakis, J.N.; Velis, C.A.; Weber, R.; Iacovidou, E.; Purnell, P. An overview of chemical additives present in plastics: Migration, release, fate and environmental impact during their use, disposal and recycling. J. Hazard. Mater. 2018, 344, 179-199. [CrossRef]

55. Bayo, J.; Martínez, A.; Guillén, M.; Olmos, S.; Roca, M.-J.; Alcolea, A. Microbeads in Commercial Facial Cleansers: Threatening the Environment. CLEAN Soil Air Water 2017, 45, 1600683. [CrossRef]

56. Teuten, E.L.; Saquing, J.M.; Knappe, D.; Barlaz, M.A.; Jonsson, S.; Björn, A.; Rowland, S.J.; Thompson, R.C.; Galloway, T.S.; Yamashita, R.; et al. Transport and release of chemicals from plastics to the environment and to wildlife. Philos. Trans. R. Soc. B: Boil. Sci. 2009, 364, 2027-2045. [CrossRef]

57. Escudero, R.; Espinoza, E.; Tavera, F.J. Precipitation of Lead Species in a $\mathrm{Pb}-\mathrm{H}_{2} \mathrm{O}$ System. Res. J. Recent. Sci. 2013, 2, 1-8.

58. Poma, P.A. Intoxicación por Plomo en Humanos. In Anales de la Facultad de Medicina; UNMSM. Facultad de Medicina: Lima, Peru, 2008; Volume 69, pp. 120-126.

59. Moore, J.H.; Christie, W.W. Chapter 6: Digestion, Absorption and Transport of Fats in Ruminant Animals. In Fats in Animal Nutrition; Wiseman, J., Ed.; Butterworths: New York, NY, USA, 1984; pp. 123-149.

60. Kim, Y.; Lee, G.; Park, S.; Kim, B.; Park, J.; Cho, J. Pressure Monitoring System in Gastro-Intestinal Tract. In Proceedings of the International Conference on Robotics and Automation, Barcelona, Spain, 18-22 April 2005; pp. 1333-1338.

61. Hasler, W.I. Small Intestinal Motility. In Physiology of the Gastro-Intestinal Tract, 4th ed.; Elsevier: Cambridge, MA, USA, 2006.

(C) 2020 by the authors. Licensee MDPI, Basel, Switzerland. This article is an open access article distributed under the terms and conditions of the Creative Commons Attribution (CC BY) license (http://creativecommons.org/licenses/by/4.0/). 